Original Research Paper

\title{
Effect of Object Size and Location on Contact Forces and Grasping Stability for an Underactuated Robotic Manipulator
}

\author{
${ }^{1}$ Somer Matti Nacy and ${ }^{2}$ Ahmed Abdulsalam Nayif \\ ${ }^{1}$ Department of Biomedical Engineering, \\ Alkhwarizmi College of Engineering, University of Baghdad, Baghdad, Iraq \\ ${ }^{2}$ Department of Manufacturing Automation, \\ Alkhwarizmi College of Engineering, University of Baghdad, Baghdad, Iraq
}

\author{
Article history \\ Received: 16-04-2018 \\ Revised: $13-05-2018$ \\ Accepted: 21-05-2018 \\ Corresponding Author: \\ Somer Matti Nacy \\ Alkhwarizmi College of \\ Engineering, University of \\ Baghdad, Baghdad, Iraq \\ Email: nacys2@asme.org
}

\begin{abstract}
This paper comprises a study of the grasping stability for an underactuated robotic manipulator under the condition of varying the position of different sizes cylindrical grasped objects. Grasping forces were calculated both theoretically and Via a CAD model for a 3-DOF underactuated robotic manipulator. The experimental part comprises the fabrication of the manipulator and performing the required tests on this manipulator by changing the position and size of the grasped object. Contact forces were observed experimentally by using the Force Sensing Resistors (FSR). Maps of stability and ejection for three different cylindrical object diameters $(160,200,240) \mathrm{mm}$ were presented. As a result, it was found that stable grasping is greatly affected by the size and location of the grasped object, where stable grasping is achieved for objects located near the actuator position.
\end{abstract}

Keywords: Underactuated Manipulator, Grasping Stability, Contact Forces

\section{Introduction}

Underactuated robotic manipulators are widely used in indusial robots, for they can be actuated by a single actuator for whatever degrees of freedom they have. The implementation of underactuation in robotic grasping seems to be more desirable for its need to simple control systems to govern less number of actuators as compared to a fully actuated system. The concept of grasping relies on providing a proficient mechanical system that can adapt to the shape of the grasped object hence to ensure stable grasping. The application of underactuated mechanisms make this concept to be more reliable and effective. The four bar mechanism is one of the common mechanisms applied in underactuated robotic grippers for their high grasping force capabilities.

Many researchers have studied underactuated manipulators as related to: Their design and analysis; Rea (2011; Yao and Ceccarelli, 2011; Nacy and Nayif, 2016; Birglen and Gosselin, 2005): Their optimization; Birglen and Gosselin (2004; Nacy et al., 2009): Their usage as grippers or robotic hands; Birglen et al. (2008; Kragten, 2011; Laliberté and Gosselin, 2003; Zhao and Zhang, 2010; Meijneke et al., 2011; Dandash et al., 2011; Jung and Oh, 2013; Azlan and Hiroshi, 2010; Laliberte et al., 2002): Their mechanism types; Carrozza et al. (2004; Yang et al., 2004; Cabas et al.,
2006; Krut, 2005; Dechev et al., 2001): Their grasping stability analysis; Kim et al. (2010; Zhang et al., 2009; Rizk et al., 2007; Ha et al., 2016; Kragten and Herder, 2007; Luo et al., 2004; Kragten et al., 2011).

In this work, grasping forces between the underactuated manipulator and a cylindrical grasped object were found for different sizes of the grasped object and at different locations on the workspace of the robotic manipulator where it can be reachable and grasped. Grasping forces distribution that clarifies the variation of grasping forces over the workspace was presented. The cases of stable grasping and ejection were obtained; hence stable grasping and ejection maps were concluded.

\section{Theoretical Analysis and Simulation}

The 3-DOF underactuated manipulator is shown schematically in Fig. 1. According to Birglen and Gosselin (2005), the equations of grasping forces can be presented as:

$$
\begin{aligned}
& f_{1}=\frac{l_{1} U T_{a}}{k_{1} k_{2} k_{3}\left(h_{2}+l_{1}\right)\left(h_{3}+l_{2}\right)}-\frac{\left(k_{2}+l_{1} \cos \theta_{2}\right) T_{2}}{k_{1} k_{2}}+\frac{l_{1} V T_{3}}{k_{1} k_{2} k_{3}} \\
& f_{2}=\frac{h_{2} l_{2}\left(k_{3}-h_{3} \cos \theta_{3}\right) T_{a}}{k_{2} k_{3}\left(h_{2}+l_{1}\right)\left(h_{3}+l_{2}\right)}+\frac{T_{2}}{k_{2}}-\frac{\left(k_{3}+l_{2} \cos \theta_{3}\right) T_{3}}{k_{2} k_{3}}
\end{aligned}
$$




$$
f_{3}=\frac{h_{2} h_{3} T_{a}}{k_{3}\left(h_{2}+l_{1}\right)\left(h_{3}+l_{2}\right)}+\frac{T_{3}}{k_{3}}
$$

With:

$$
\begin{aligned}
U= & k_{2} k_{3} h_{3}+k_{2} k_{3} l_{2}-h_{2} k_{3} l_{2} \cos \theta_{2}+h_{2} h_{3} l_{2} \cos \theta_{2} \cos \theta_{3} \\
& -h_{2} h_{3} k_{2} \cos \left(\theta_{2}+\theta_{3}\right) \\
V= & l_{2} \cos \theta_{2} \cos \theta_{3}+k_{3} \cos \theta_{2}-k_{2} \cos \left(\theta_{2}+\theta_{3}\right) \\
h_{i}= & c_{i-1}\left(\cos \left(\theta_{i}-\varphi_{i}\right)-\sin \left(\theta_{i}-\varphi_{i}\right) \cot \beta_{i-1}\right)
\end{aligned}
$$

Where:

$T_{a}: \quad$ Torque of the actuator

$T_{2}$ : $\quad$ Torque of spring 1
$T_{3}$ : $\quad$ Torque of spring 2

$f_{1}, f_{2}, f_{3}$ : Normal forces of proximal, middle and distal phalanges respectively

$l_{1}, l_{2}, l_{3}$ : Length of proximal, middle and distal phalanges respectively

$k_{1}, k_{2}, k_{3}$ : Contact locations on their respective phalanges $\theta_{2}, \theta_{2}$ : Angles between the phalanges

Contact forces $f_{1}, f_{2}, f_{3}$ can be calculated according to a given geometrical dimensions of the manipulator, as listed in table 1, size and location of the grasped cylindrical object. Hence, in order to achieve a stable

\begin{tabular}{|c|c|c|c|c|c|c|c|c|c|c|}
\hline$\underline{l_{1}}$ & $l_{2}$ & $l_{3}$ & $a_{1}$ & $b_{1}$ & $c_{1}$ & $a_{2}$ & $b_{2}$ & $c_{2}$ & $\mathrm{~S}$ & $K_{1}, K_{2}$ \\
\hline $266 \mathrm{~mm}$ & $265 \mathrm{~mm}$ & $233 \mathrm{~mm}$ & $220 \mathrm{~mm}$ & $278 \mathrm{~mm}$ & $151 \mathrm{~mm}$ & $272 \mathrm{~mm}$ & $283 \mathrm{~mm}$ & $175 \mathrm{~mm}$ & $85.6 \mathrm{~mm}$ & $46 \mathrm{~N} / \mathrm{m}$ \\
\hline
\end{tabular}
grasping situation, all these forces have to be positive. The simulation model, shown in Fig. 2 was built using MSC Visual Nastran.

Table 1: Design parameters of the manipulator

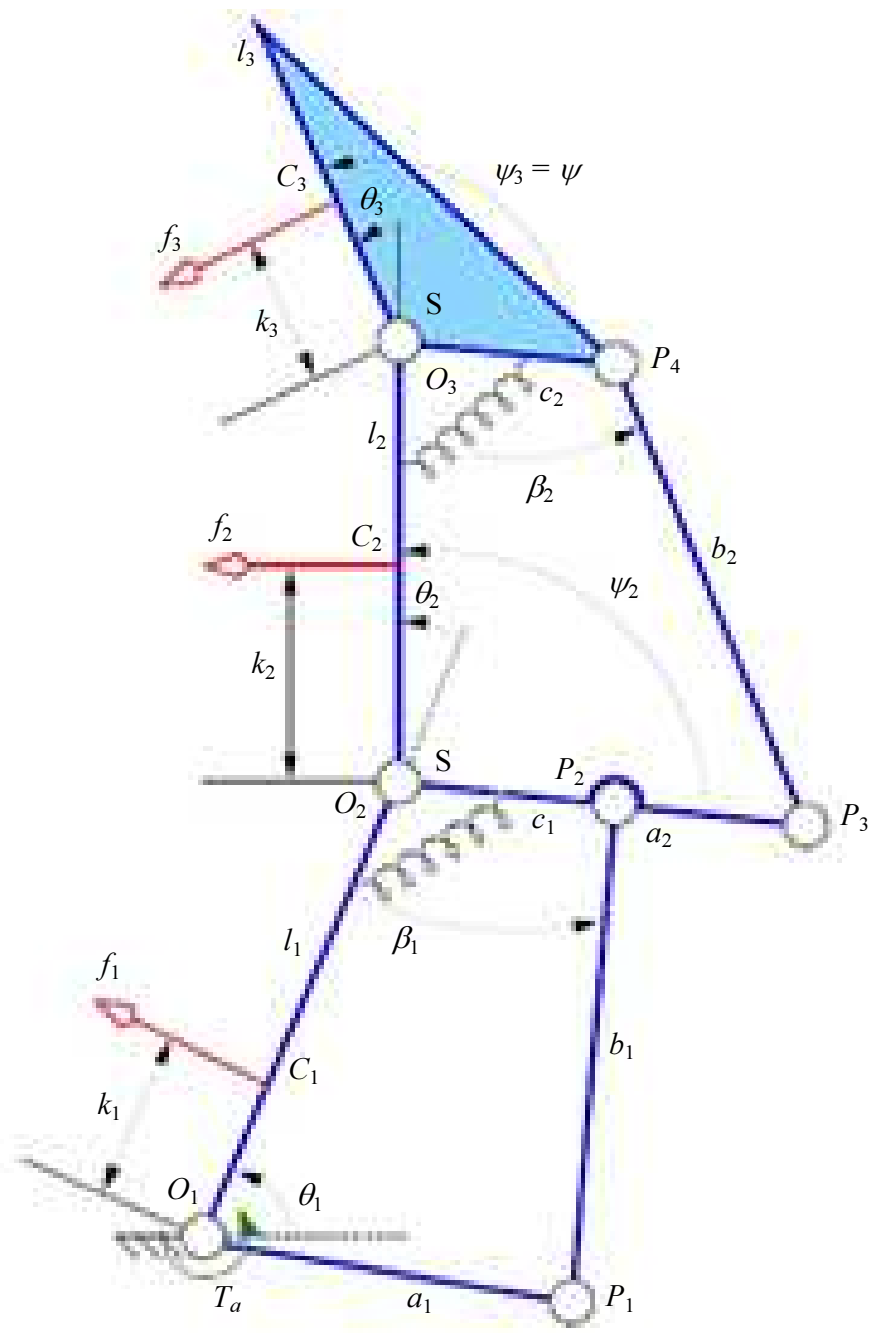

Fig. 1: 3-DOF linkage type underactuated manipulator 


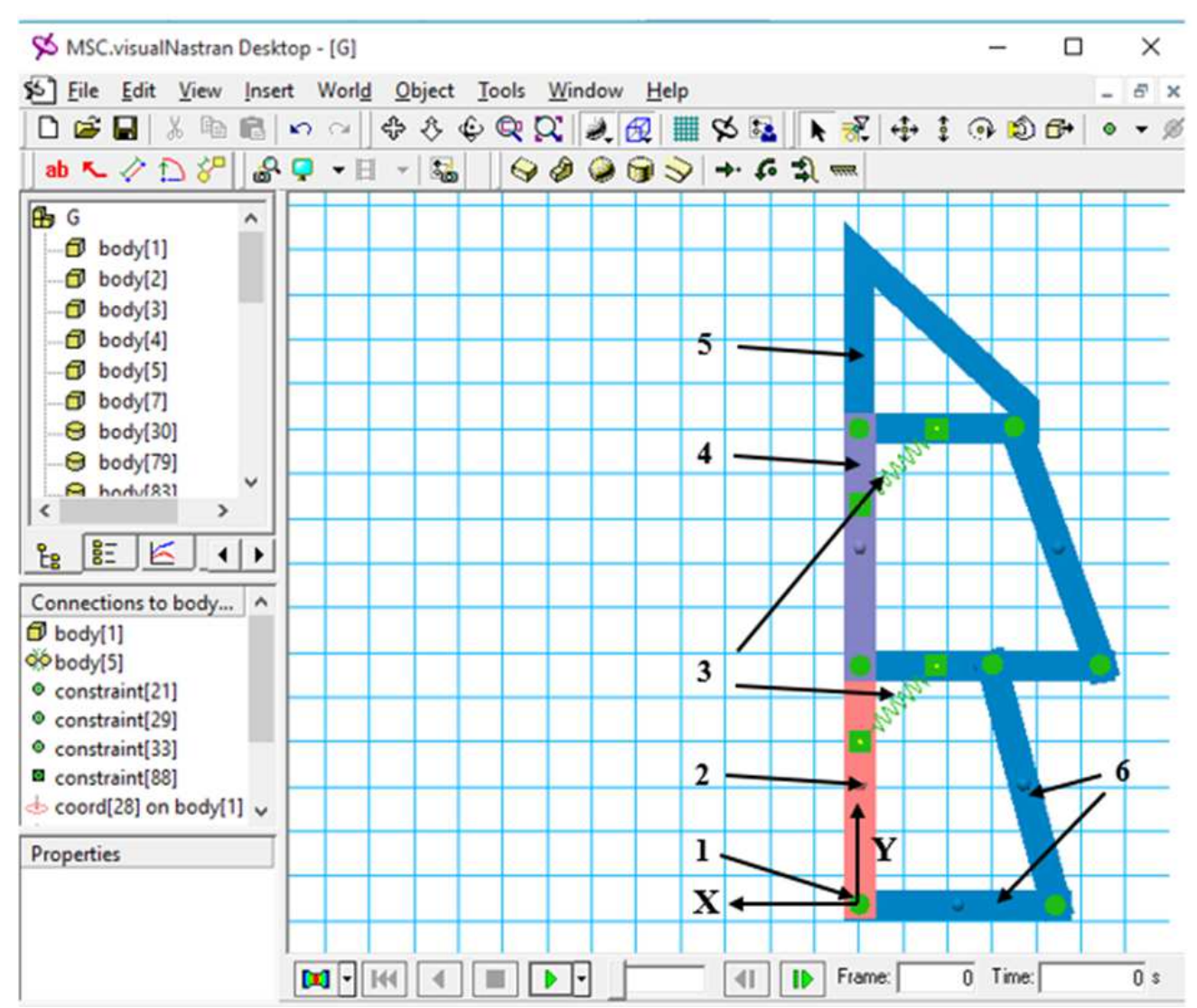

Fig. 2: Model of the underactuated manipulator; (1) Rotary actuator, (2) Proximal link, (3) Identical springs, (4) Middle link, (5) Distal link, (6) Transmission mechanism

\section{Experimentation}

The links of the underactuated manipulator were made from plastic material. Rotary actuator was used to actuate this manipulator. Ball bearings were placed in the joints to ensure smooth movement of the links. Springs were added to the second and third joints. Moreover, the force sensor FSR type interlink 408 was attached at the surfaces of contact between the links and the grasped object, which was associated with Arduino UNO board to get the results of contact forces.

The experimental setup for the underactuated robotic manipulator is illustrated in Fig. 3. It consists of (1) the linkage mechanism, (2) the actuator, (3) power supply, (4) springs, (5) ball bearings, (6) the grasped object, (7) Arduino UNO and (8) Force Sensing Resistors (FSR).

The grasped cylindrical objects were in three different diameters, namely, 160, 200 and $240 \mathrm{~mm}$. The plane on which the cylindrical object is to be placed then grasped by the manipulator, which can be considered as the grasping work space, is $764 \times 764$ $\mathrm{mm}$ in dimension.

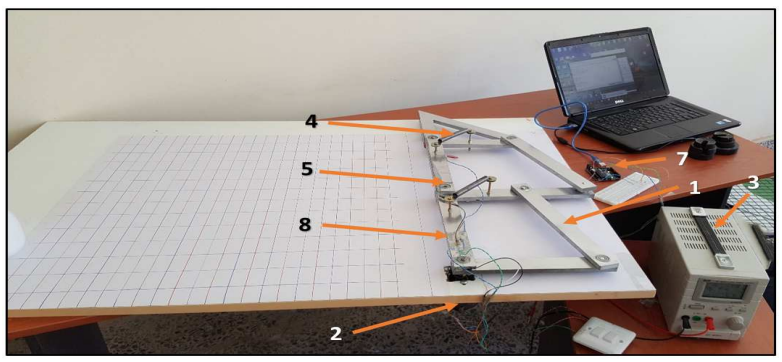

Fig. 3:3-DOF Underactuated robotic manipulator with all required instruments

\section{Results and Discussion}

As stated previously grasping forces were obtained by three different procedures, theoretical, experimental and simulation, for three different sizes of the cylindrical grasped objects, $\mathrm{D}=160,200,240 \mathrm{~mm}$, located at different positions as related to the actuator of the grasping robotic manipulator. For comparison purposes, sample of these forces are shown in Tables 2, 3 and 4. All the cases listed in these tables are those representing stable grasping condition, in which the forces are all 
positive thus insuring contact occurrence between the robotic manipulator and the grasped object. In case of stable grasping, it can be seen that depending on the object size or object location, contact occurs at link 1 , link 2, link 3, at two links, or at all three links. While for the case in which ejection occurs, there will be no grasping where this case can be considered as unstable, as depicted in Fig. 4.

Table 2: Grasping Forces for cylindrical object $\mathrm{D}=160 \mathrm{~mm}$

\begin{tabular}{|c|c|c|c|c|c|c|c|c|c|c|c|c|c|}
\hline \multicolumn{2}{|c|}{ POS (m) } & \multicolumn{3}{|c|}{ Theoretical $(\mathrm{N})$} & \multicolumn{3}{|c|}{ Simulation $(\mathrm{N})$} & \multicolumn{3}{|c|}{ Experimental (N) } & \multicolumn{3}{|c|}{$\%$ Error } \\
\hline$X$ & $\mathrm{Y}$ & $\mathrm{F} 1$ & $\mathrm{~F} 2$ & F3 & $\mathrm{F} 1$ & $\mathrm{~F} 2$ & F3 & $\mathrm{F} 1$ & $\mathrm{~F} 2$ & F3 & $\mathrm{F} 1$ & $\mathrm{~F} 2$ & F3 \\
\hline 0.100 & 0.131 & 21.10 & - & - & 20.96 & - & - & 19.27 & - & - & 8.1 & - & - \\
\hline 0.100 & 0.231 & 4.43 & 16.31 & 0.49 & 5.48 & 12.00 & 0.88 & 5.11 & 11.94 & 1.04 & 6.8 & 0.5 & 15.4 \\
\hline 0.100 & 0.281 & - & 11.10 & 0.91 & - & 11.00 & 1.04 & - & 10.78 & 0.98 & - & 2.0 & 5.80 \\
\hline 0.100 & 0.381 & - & 7.67 & 3.42 & - & 7.43 & 3.21 & - & 8.10 & 3.12 & - & 8.3 & 2.80 \\
\hline 0.100 & 0.581 & - & - & 6.08 & - & - & 5.54 & - & - & 5.23 & - & - & 5.60 \\
\hline 0.150 & 0.231 & - & 11.59 & 0.66 & - & 11.66 & 0.95 & - & 12.02 & 1.10 & - & 3.0 & 13.6 \\
\hline 0.150 & 0.181 & 12.84 & - & 0.47 & 12.31 & - & 0.81 & 10.94 & - & 0.82 & 11.1 & - & 1.20 \\
\hline 0.200 & 0.081 & 7.09 & 9.76 & - & 10.54 & 3.30 & - & 8.89 & 2.83 & - & 15.7 & 14.2 & - \\
\hline 0.204 & 0.141 & 12.47 & 24.74 & 0.50 & 12.94 & 9.36 & 0.32 & 10.93 & 11.38 & 0.36 & 15.5 & 9.8 & 11.1 \\
\hline 0.200 & 0.081 & 5.27 & 17.22 & 0.49 & 6.92 & 15.87 & 0.87 & 5.94 & 13.84 & 1.02 & 14.2 & 12.8 & 14.7 \\
\hline 0.300 & 0.031 & - & 10.58 & 0.90 & - & 10.56 & 1.19 & - & 10.14 & 1.12 & - & 4.0 & 5.9 \\
\hline 0.300 & 0.131 & - & 9.84 & 1.24 & - & 9.66 & 1.47 & - & 10.18 & 1.57 & - & 5.1 & 6.40 \\
\hline
\end{tabular}

Table 3: Grasping Forces for Cylindrical Object D $=200 \mathrm{~mm}$

\begin{tabular}{|c|c|c|c|c|c|c|c|c|c|c|c|c|c|}
\hline \multicolumn{2}{|c|}{ POS (m) } & \multicolumn{3}{|c|}{ Theoretical (N) } & \multicolumn{3}{|c|}{ Simulation $(\mathrm{N})$} & \multicolumn{3}{|c|}{ Experimental (N) } & \multicolumn{3}{|c|}{$\%$ Error } \\
\hline$\underline{X}$ & $\mathrm{Y}$ & $\mathrm{F} 1$ & $\mathrm{~F} 2$ & F3 & F1 & $\mathrm{F} 2$ & F3 & $\mathrm{F} 1$ & $\mathrm{~F} 2$ & $\mathrm{~F} 3$ & $\mathrm{~F} 1$ & $\mathrm{~F} 2$ & F3 \\
\hline 0.125 & 0.131 & 20.910 & - & - & 20.32 & - & - & 19.48 & - & - & 4.1 & - & - \\
\hline 0.125 & 0.181 & 15.850 & - & 0.59 & 15.59 & - & 0.58 & 14.72 & - & 0.68 & 5.6 & - & 14.7 \\
\hline 0.125 & 0.215 & 1.600 & 13.54 & 0.62 & 2.19 & 12.00 & 1.20 & 2.02 & 11.85 & 1.12 & 7.8 & 1.3 & 6.7 \\
\hline 0.125 & 0.281 & - & 12.96 & 1.83 & - & 10.22 & 2.14 & - & 10.08 & 1.94 & - & 1.4 & 9.3 \\
\hline 0.125 & 0.531 & - & - & 7.45 & - & - & 7.16 & - & - & 7.01 & - & - & 2.1 \\
\hline 0.175 & 0.331 & - & 7.98 & 2.71 & - & 7.64 & 2.45 & - & 7.14 & 2.08 & - & 6.5 & 15.1 \\
\hline 0.175 & 0.181 & 0.320 & 10.88 & 0.72 & 0.48 & 10.90 & 0.96 & 0.51 & 10.10 & 1.14 & 5.9 & 7.3 & 15.8 \\
\hline 0.175 & 0.081 & 20.040 & - & 0.50 & 19.50 & - & 0.38 & 19.04 & - & 0.42 & 2.4 & - & 9.5 \\
\hline 0.225 & 0.031 & 4.770 & 9.91 & - & 11.44 & 2.25 & - & 10.38 & 2.06 & - & 9.3 & 8.4 & - \\
\hline 0.23 & 0.095 & 0.880 & 10.78 & 0.70 & 0.74 & 10.27 & 0.88 & 0.70 & 8.94 & 1.02 & 5.4 & 13.0 & 13.7 \\
\hline 0.225 & 0.431 & - & - & 10.24 & - & - & 9.94 & - & - & 10.10 & - & - & 1.6 \\
\hline
\end{tabular}

Table 4: Grasping Forces for Cylindrical Object D $=240 \mathrm{~mm}$

\begin{tabular}{|c|c|c|c|c|c|c|c|c|c|c|c|c|c|}
\hline \multicolumn{2}{|c|}{ POS (m) } & \multicolumn{3}{|c|}{ Theoretical (N) } & \multicolumn{3}{|c|}{ Simulation (N) } & \multicolumn{3}{|c|}{ Experimental (N) } & \multicolumn{3}{|c|}{$\%$ Error } \\
\hline $\mathrm{X}$ & $\mathrm{Y}$ & F1 & $\mathrm{F} 2$ & $\mathrm{~F} 3$ & F1 & $\mathrm{F} 2$ & F3 & F1 & $\mathrm{F} 2$ & F3 & $\mathrm{F} 1$ & $\mathrm{~F} 2$ & F3 \\
\hline 0.150 & 0.081 & 32.86 & - & - & 32.73 & - & - & 30.21 & - & - & 7.7 & - & - \\
\hline 0.150 & 0.131 & 14.32 & 5.49 & - & 14.25 & 3.23 & - & 13.74 & 3.16 & - & 3.6 & 2.2 & - \\
\hline 0.150 & 0.181 & 15.88 & - & 0.84 & 15.59 & - & 0.86 & 14.36 & - & 0.90 & 7.9 & - & 4.4 \\
\hline 0.138 & 0.214 & 1.51 & 9.57 & 0.95 & 1.79 & 10.61 & 1.13 & 2.03 & 10.17 & 1.10 & 11.8 & 4.1 & 2.7 \\
\hline 0.150 & 0.381 & - & 5.77 & 5.89 & - & 5.51 & 5.72 & - & 5.15 & 5.20 & - & 6.5 & 9.1 \\
\hline 0.189 & 0.171 & 2.20 & 8.78 & 0.88 & 2.39 & 8.68 & 1.06 & 2.10 & 8.17 & 1.14 & 12.1 & 5.9 & 7.0 \\
\hline 0.200 & 0.131 & 14.65 & - & 0.84 & 14.41 & - & 0.75 & 14.19 & - & 0.71 & 1.5 & - & 5.3 \\
\hline 0.246 & 0.033 & 0.32 & 12.36 & 0.97 & 0.45 & 12.39 & 1.17 & 0.53 & 11.25 & 1.07 & 15.1 & 9.2 & 8.5 \\
\hline 0.244 & 0.081 & 1.36 & 9.36 & 0.90 & 1.62 & 9.21 & 1.08 & 1.87 & 8.92 & 1.01 & 13.4 & 3.1 & 6.5 \\
\hline 0.214 & 0.131 & 1.46 & 10.45 & 0.96 & 1.23 & 10.57 & 1.11 & 1.12 & 10.02 & 1.04 & 8.9 & 5.2 & 6.3 \\
\hline 0.300 & 0.031 & - & 9.58 & 1.40 & - & 9.26 & 1.53 & - & 10.20 & 1.30 & - & 9.2 & 15.0 \\
\hline 0.500 & 0.031 & - & - & 7.49 & - & - & 6.86 & - & - & 6.11 & - & - & 10.9 \\
\hline
\end{tabular}




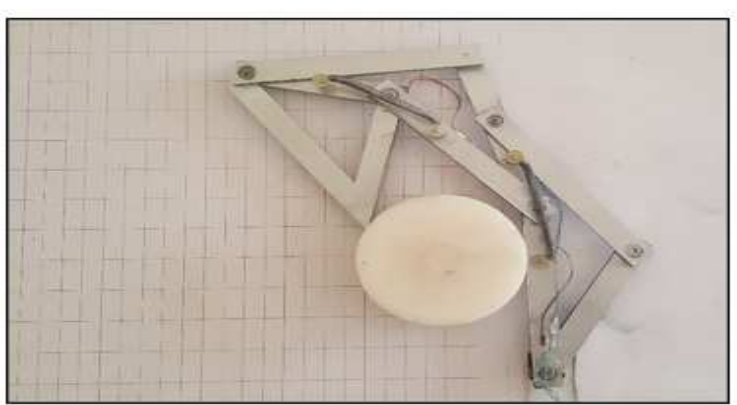

(A)

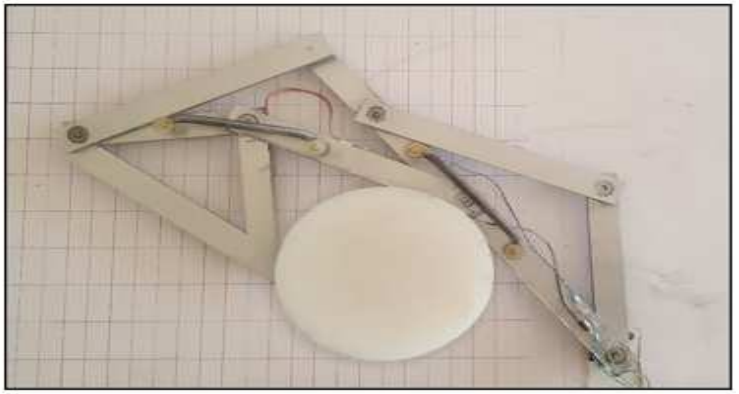

(B)

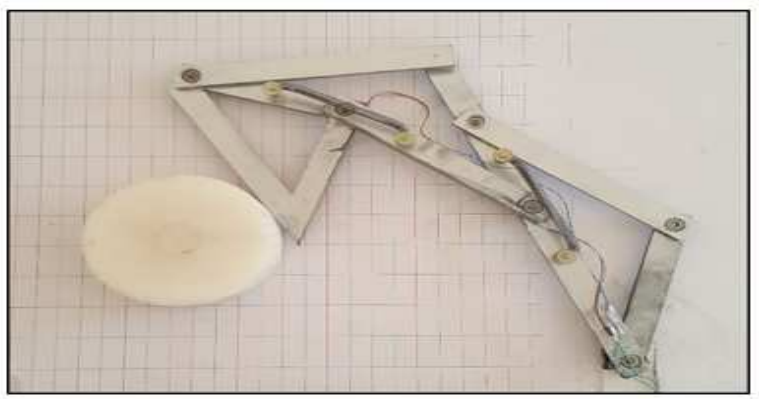

(C)

Fig. 4: Stable grasping and ejection, (A) and (B) stable grasping, (C) ejection

Although there exist some deviations in the values of forces obtained by the three procedures, but still linkage contact sequence is achieved in the same manner for the three adopted procedures of contact force calculation. These deviations in the values of contact forces are mainly due to the ignorance of friction at the contact surfaces between the links and the grasped object, in the mathematical and simulation models.

The obtained grasping forces are plotted in a 3-D view, as shown in Fig. 5 to 13 , representing their variation with the grasped object location on the working plane of the robotic manipulator.

As a common result, it can be seen that for all sizes of the cylindrical grasped object, the forces on the three links have maximum values when the location of the cylindrical object is near the actuator of the robotic manipulator, in other words near the fixed center of rotation at the base of the robotic manipulator. This happens to be true in order to balance the torque applied on the robotic manipulator by the single actuator governing the motion of the linkages mechanism.

As the contact region between any link and the grasped object goes farther from the fixed center of rotation of the manipulator, that is to say, contacts happened to be on link 2 or link 3 . It can be seen that the maximum contact force, whether $F_{2}$ or $F_{3}$ happened to be at object locations near the intersecting axes of the fixed center of rotation of the robotic manipulator.

To determine the object location on the robotic manipulator working space, hence to ensure a case of stable grasping, stability maps are plotted as shown in Fig. 14 to 16. Each figure represents a case of the cylindrical object size taken into consideration in this study, i.e., $d=160,200,240 \mathrm{~mm}$.

According to the number of degrees of freedom, the grasping workspace can be divided into three regions distributed radially. The first region is limited by the length of the proximal phalange (link 1), the second region is limited by the length of the middle phalange (link 2) and finally the third region is limited by the length of the distal phalange (link 3). From the results obtained for the three cylinders, it can be seen that grasping is fully achieved at the first region, while it decreases gradually as moving farther on the second and third regions. This is true, since when the cylindrical object is located on the first region, the three contact forces induced from the three links are acting on the grasped object thus giving rise to a stable grasp with no occurrence of ejection. Considering the area of the stable grasping region inside the workspace as a measure for the overall stability behavior, then it can be observed that stability decreases as the cylindrical grasped object becomes larger. Hence larger objects are more vulnerable to ejection as compared to small or medium size objects. 


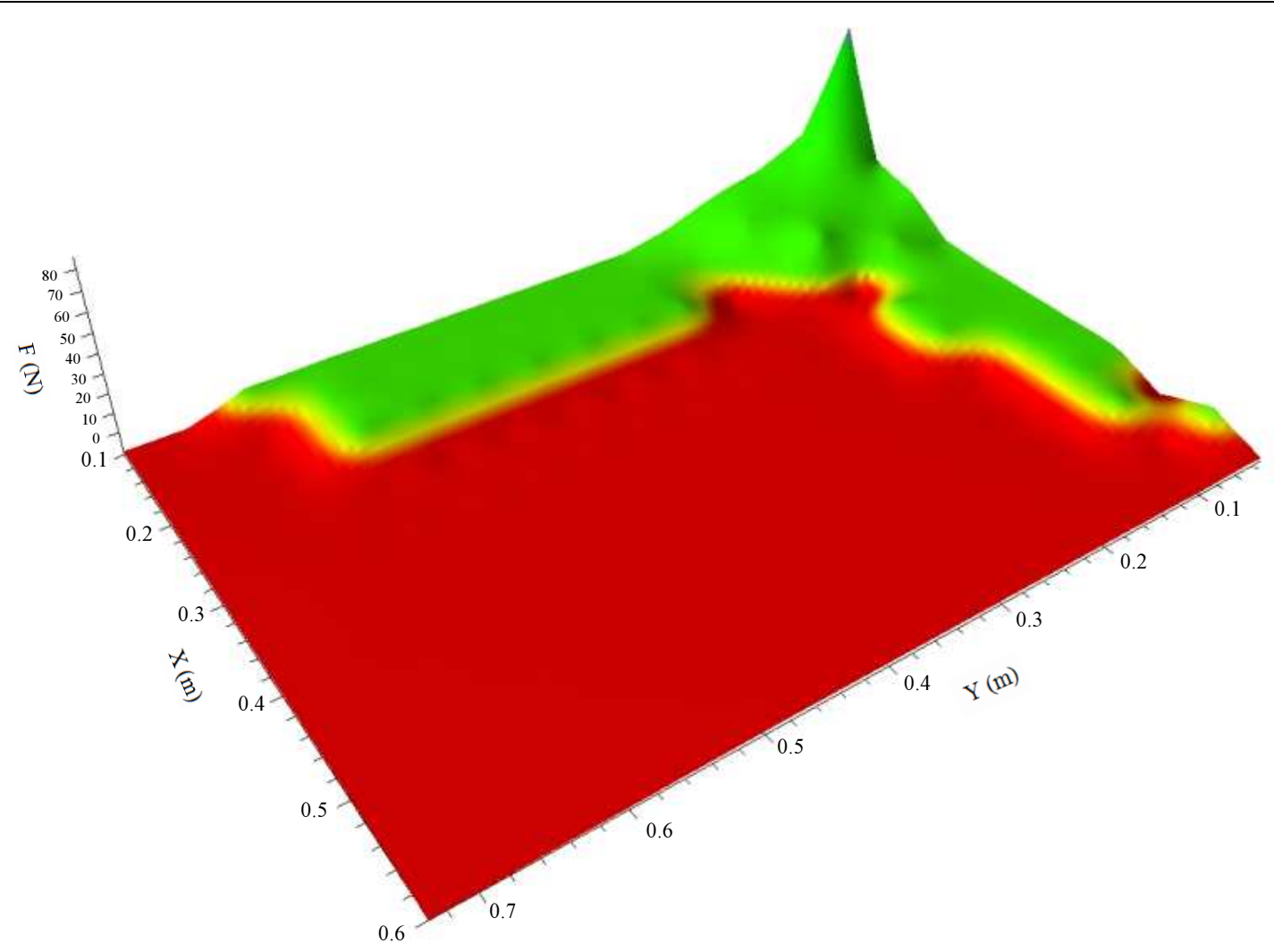

Fig. 5: Variation of force on link 1 with cylindrical object location $(d=160 \mathrm{~mm})$

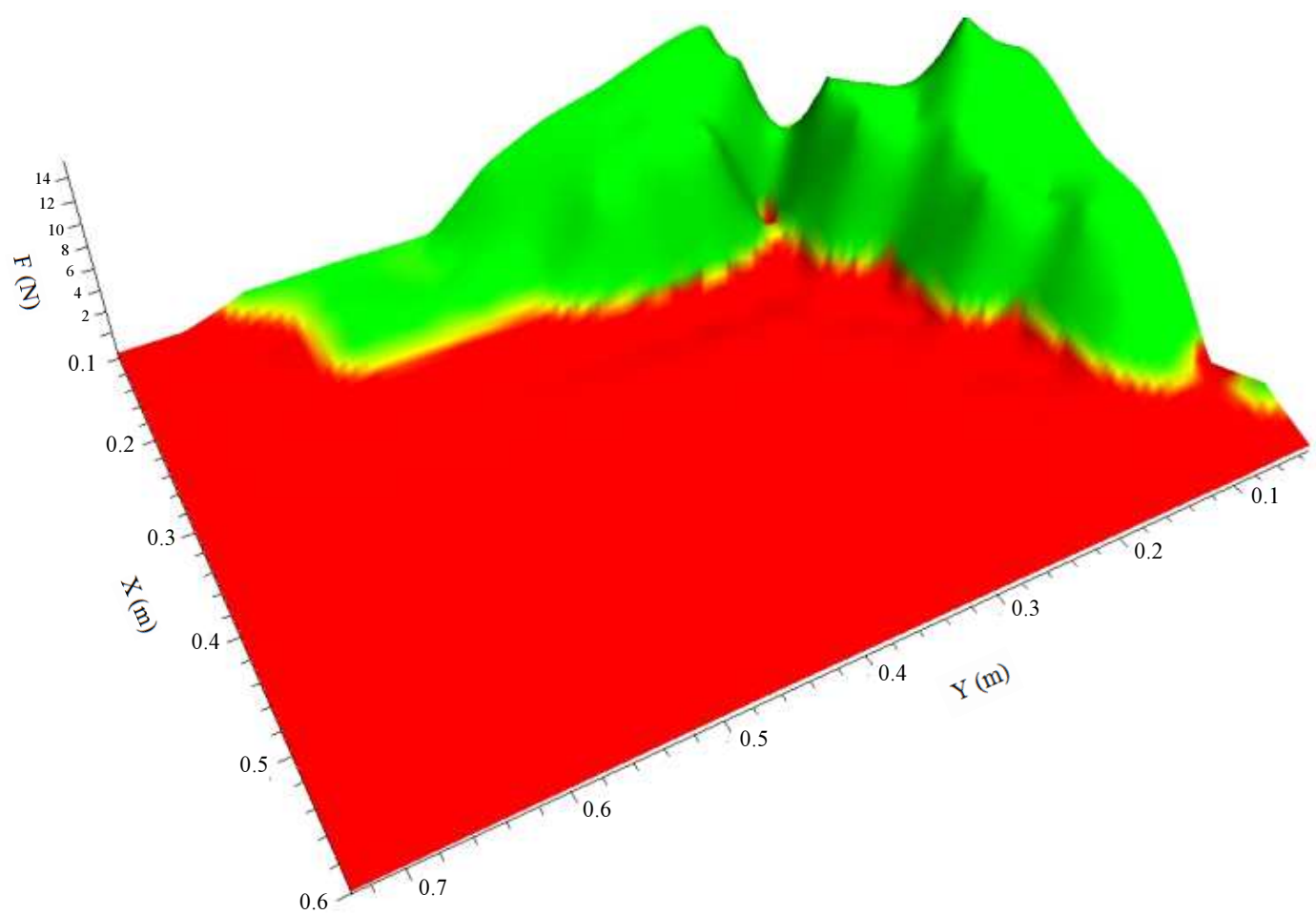

Fig. 6: Variation of force on link 2 with cylindrical object location $(\mathrm{d}=160 \mathrm{~mm})$ 


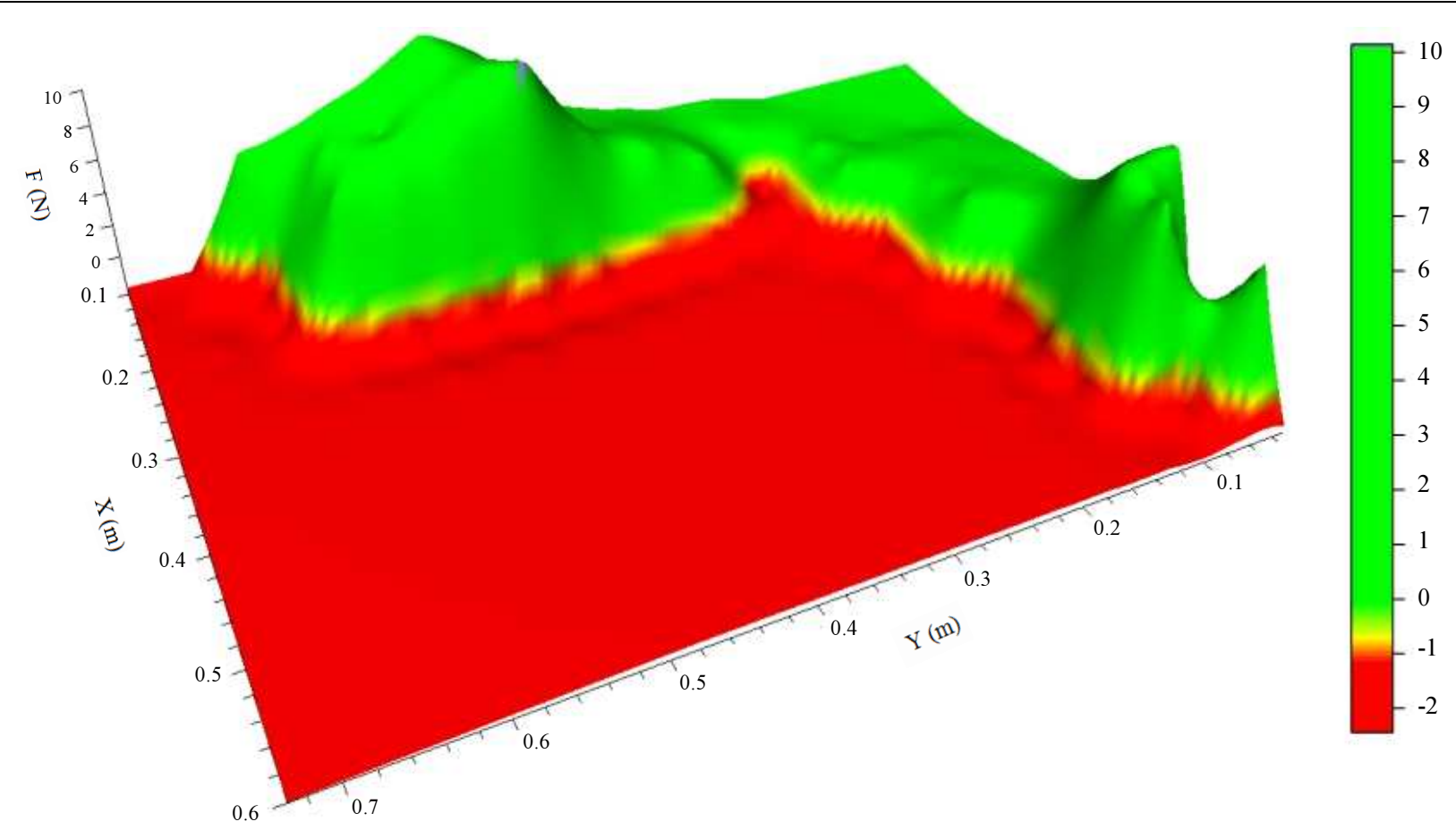

Fig. 7: Variation of force on link 3 with cylindrical object location $(\mathrm{d}=160 \mathrm{~mm})$

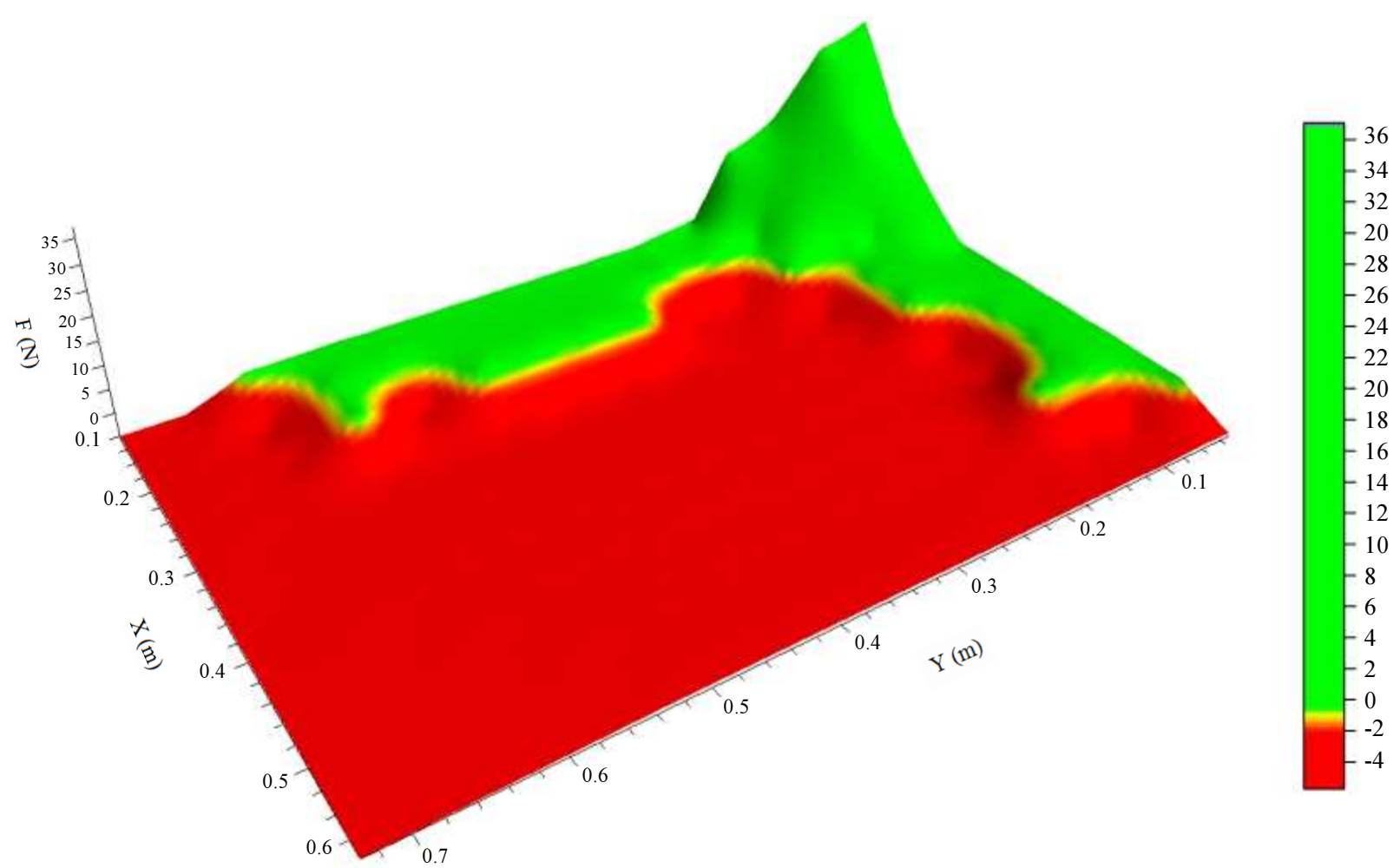

Fig. 8: Variation of force on link 1 with cylindrical object location $(\mathrm{d}=200 \mathrm{~mm})$ 


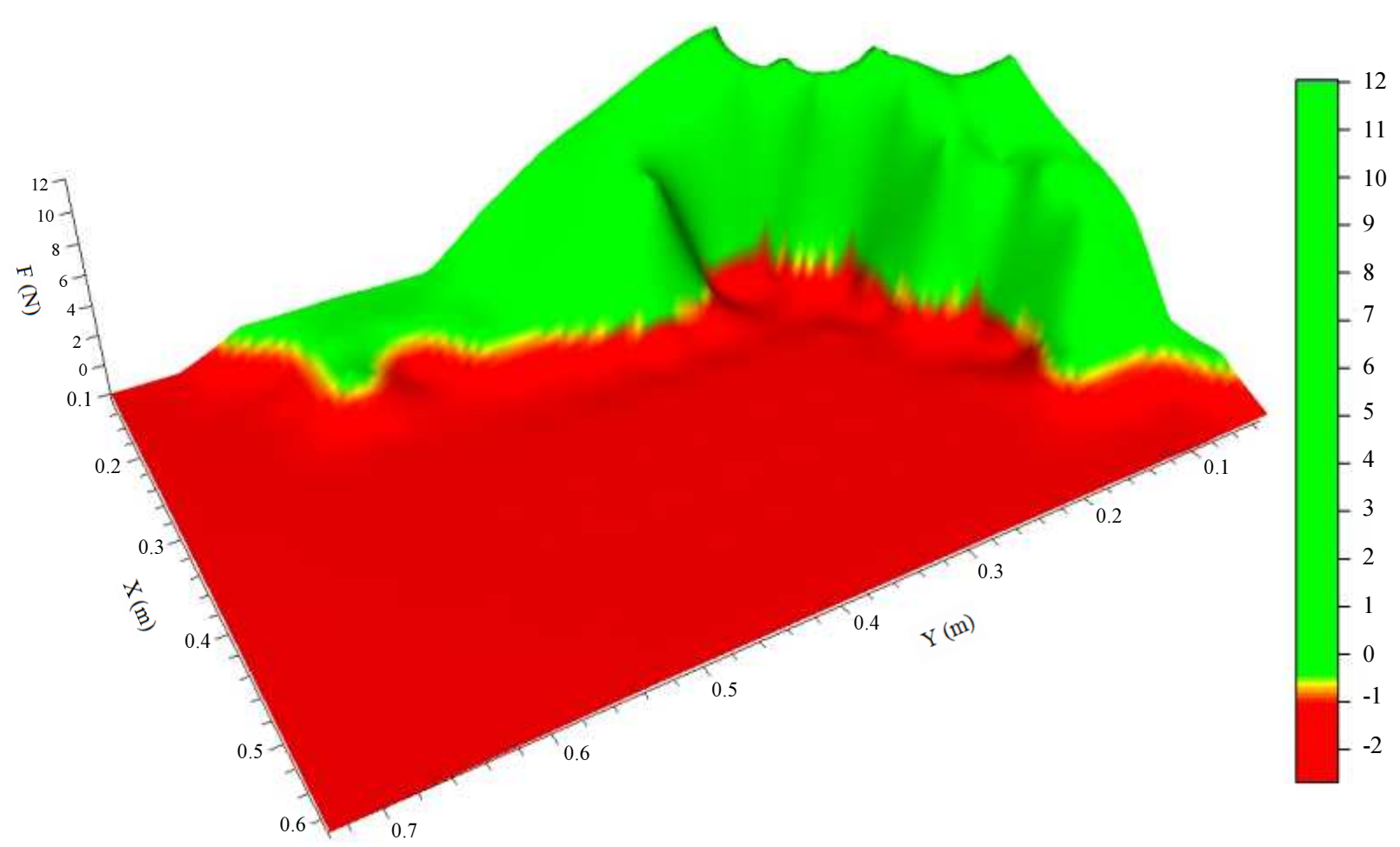

Fig. 9: Variation of force on link 2 with cylindrical object location $(\mathrm{d}=200 \mathrm{~mm})$

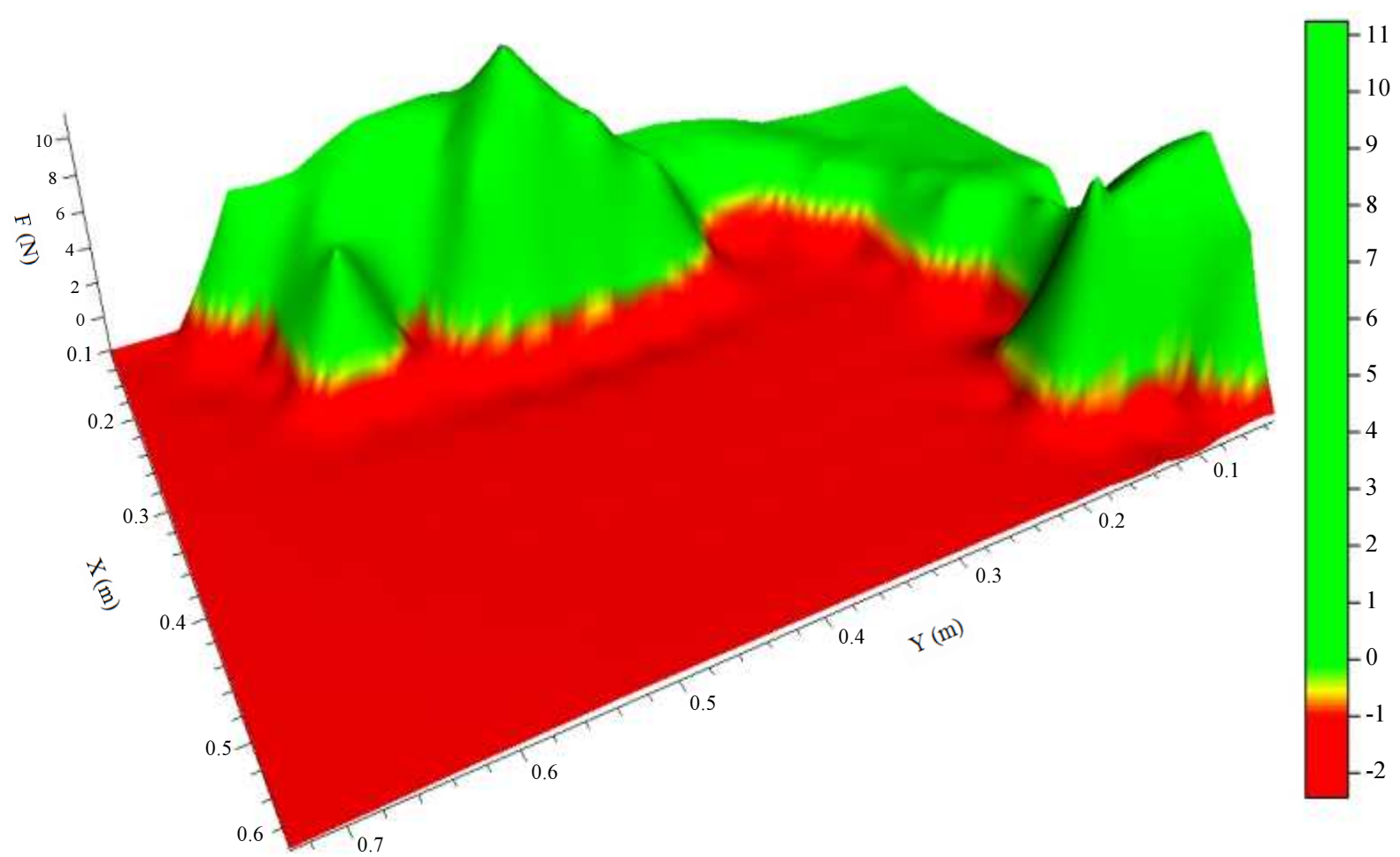

Fig. 10: Variation of force on link 3 with cylindrical object location $(\mathrm{d}=200 \mathrm{~mm})$ 


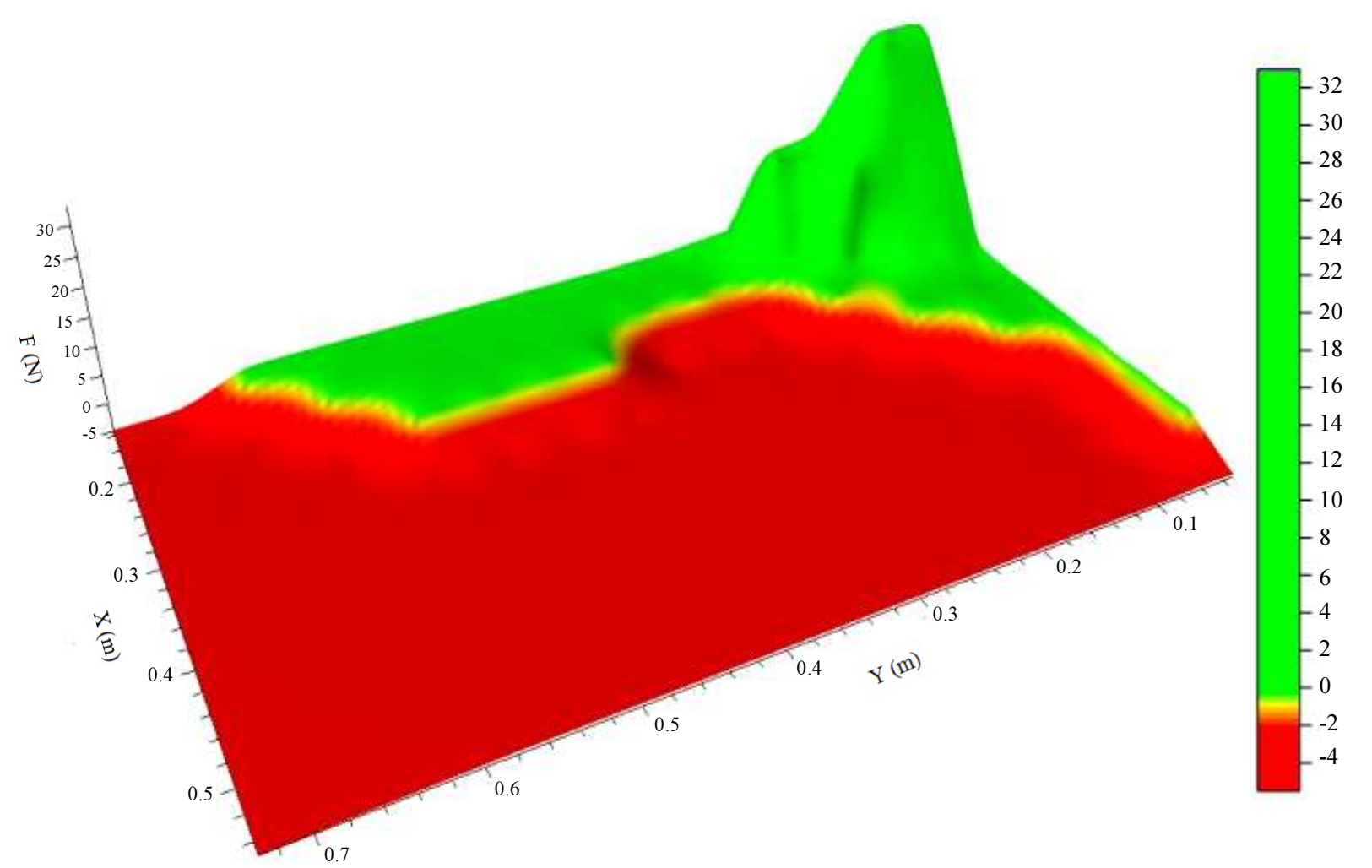

Fig. 11: Variation of force on link 1 with cylindrical object location $(d=240 \mathrm{~mm})$

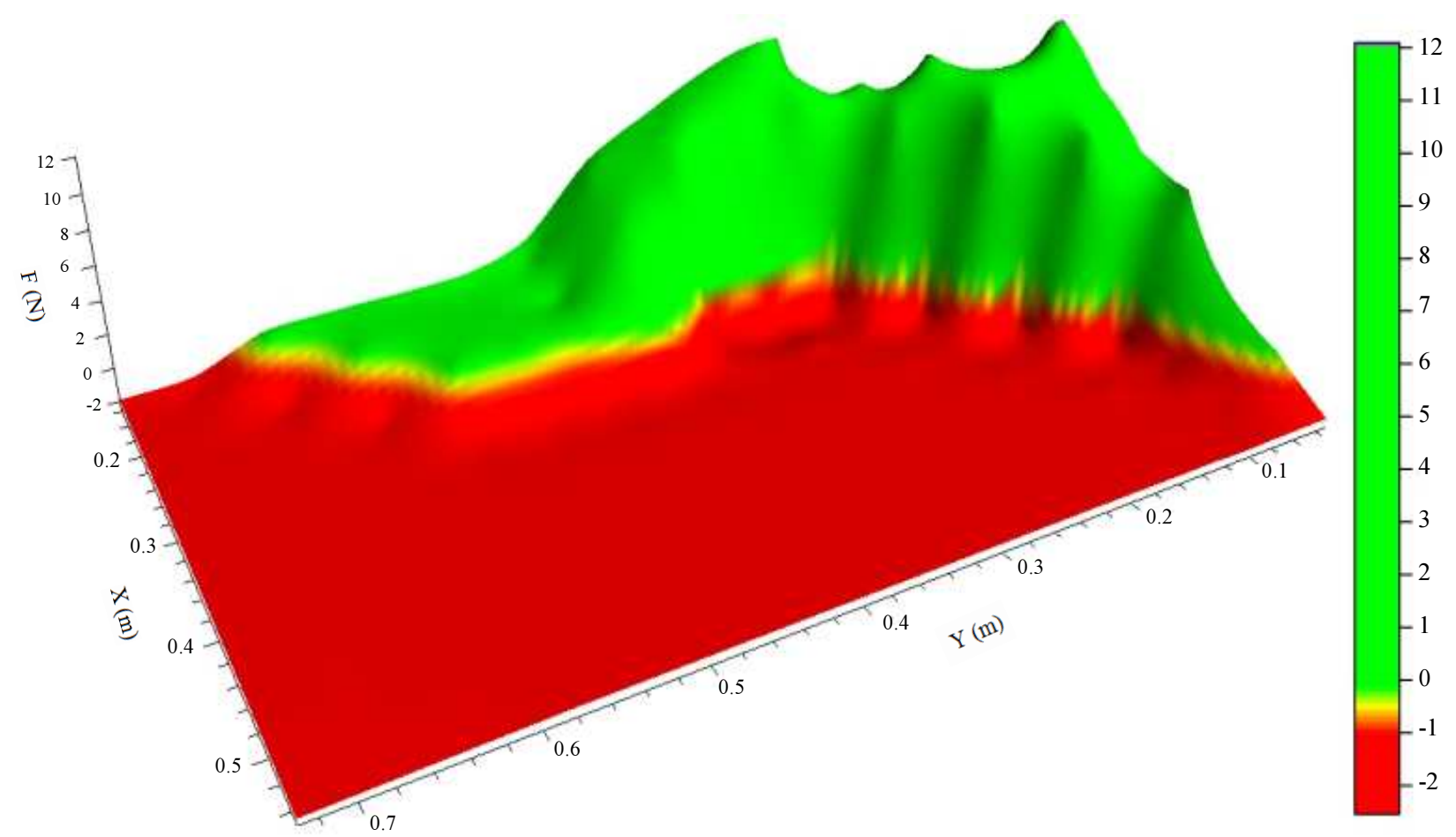

Fig. 12: Variation of force on link 2 with cylindrical object location $(\mathrm{d}=240 \mathrm{~mm})$ 


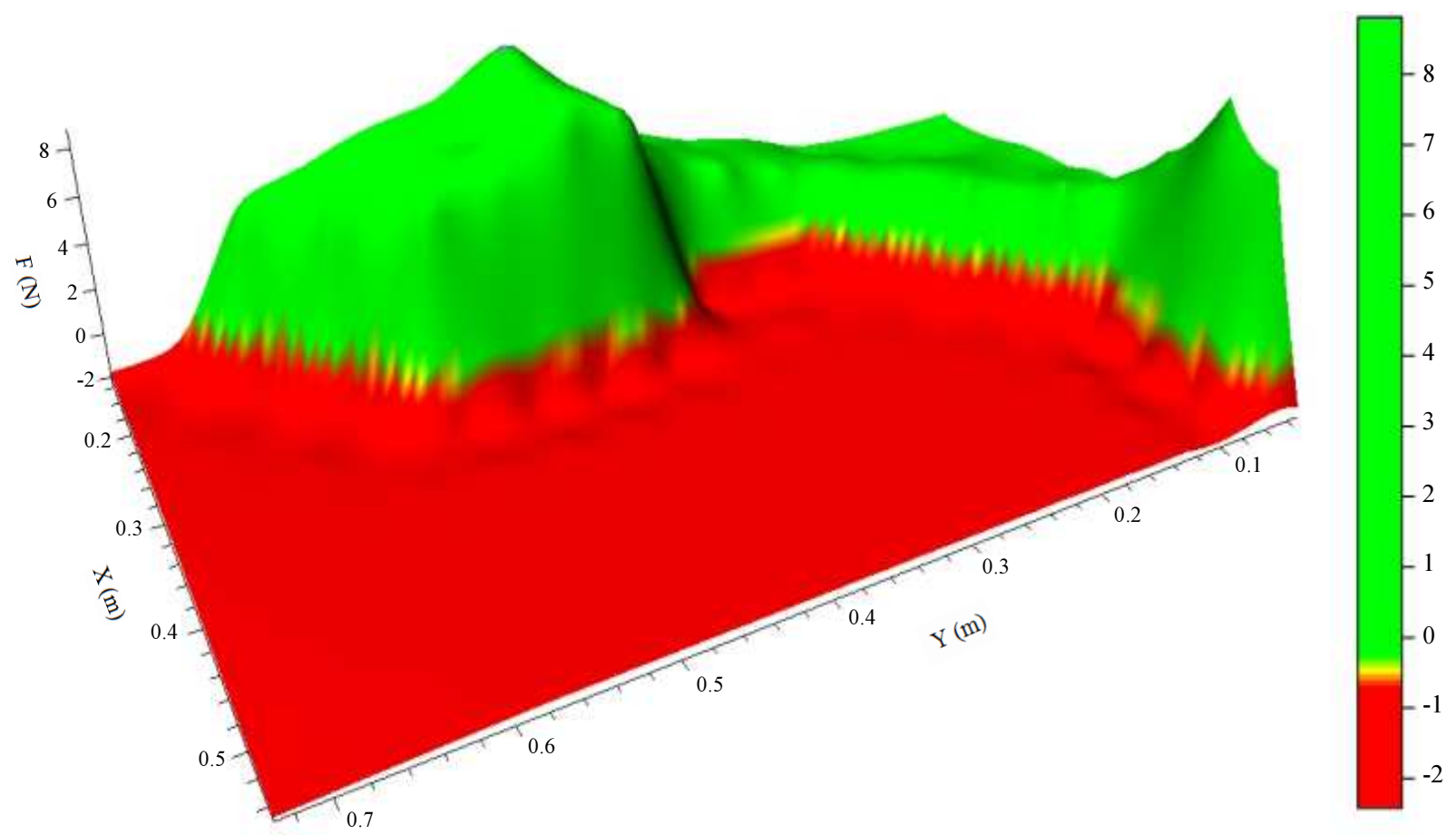

Fig. 13: Variation of force on link 3 with cylindrical object location $(\mathrm{d}=240 \mathrm{~mm})$

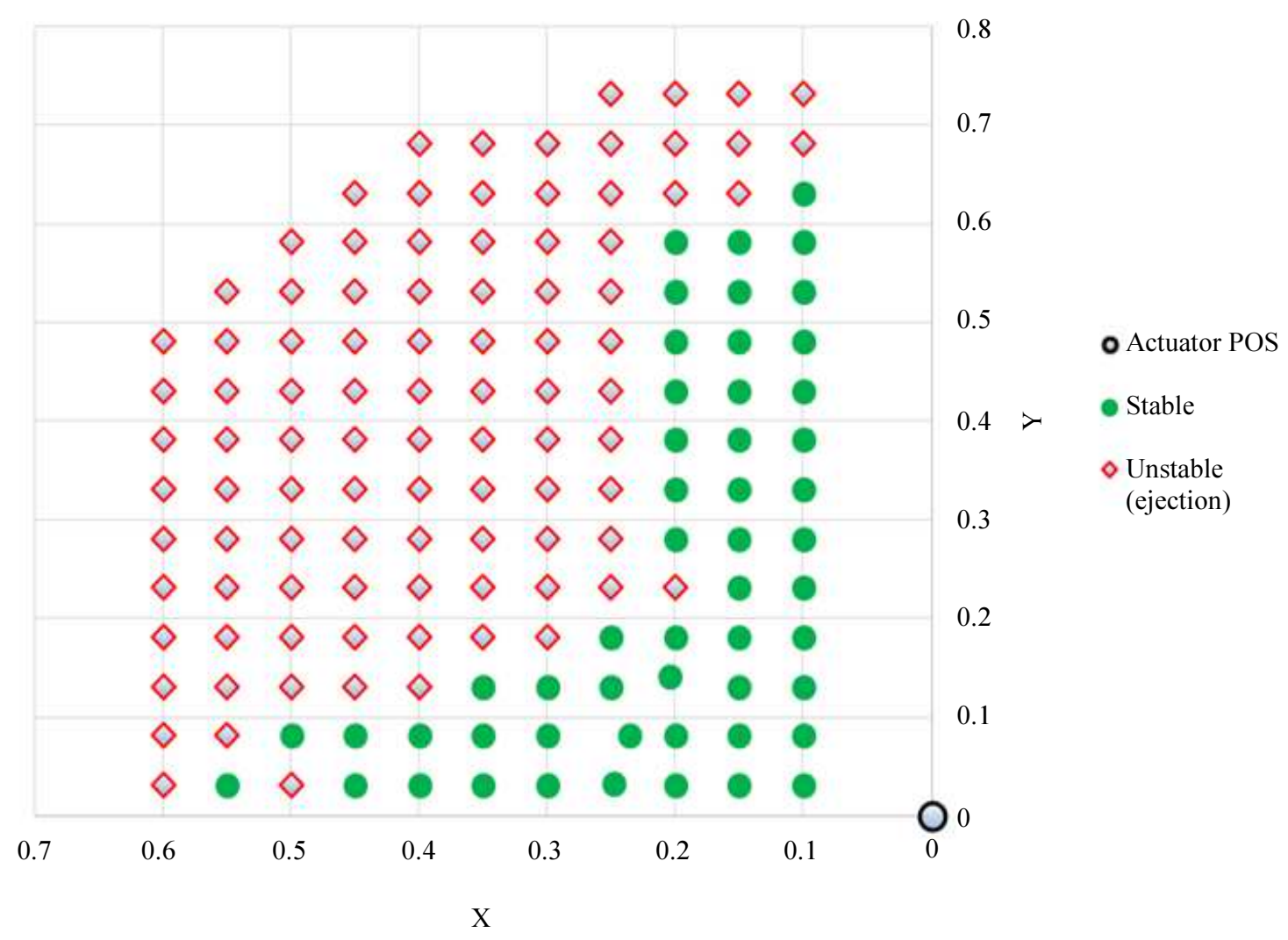

Fig. 14: Stability map for cylindrical object $d=160 \mathrm{~mm}$ 


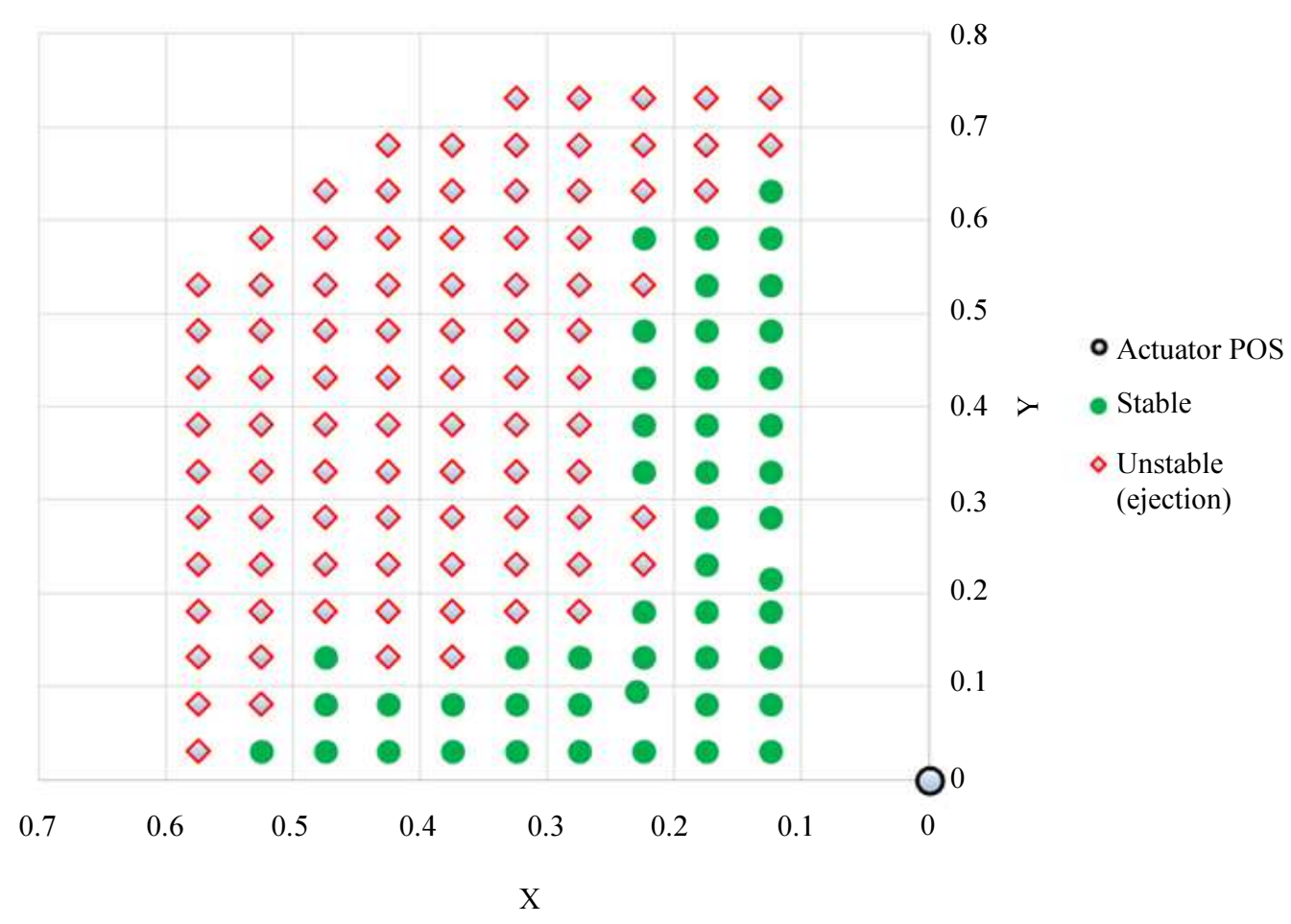

Fig. 15: Stability map for cylindrical object $d=200 \mathrm{~mm}$

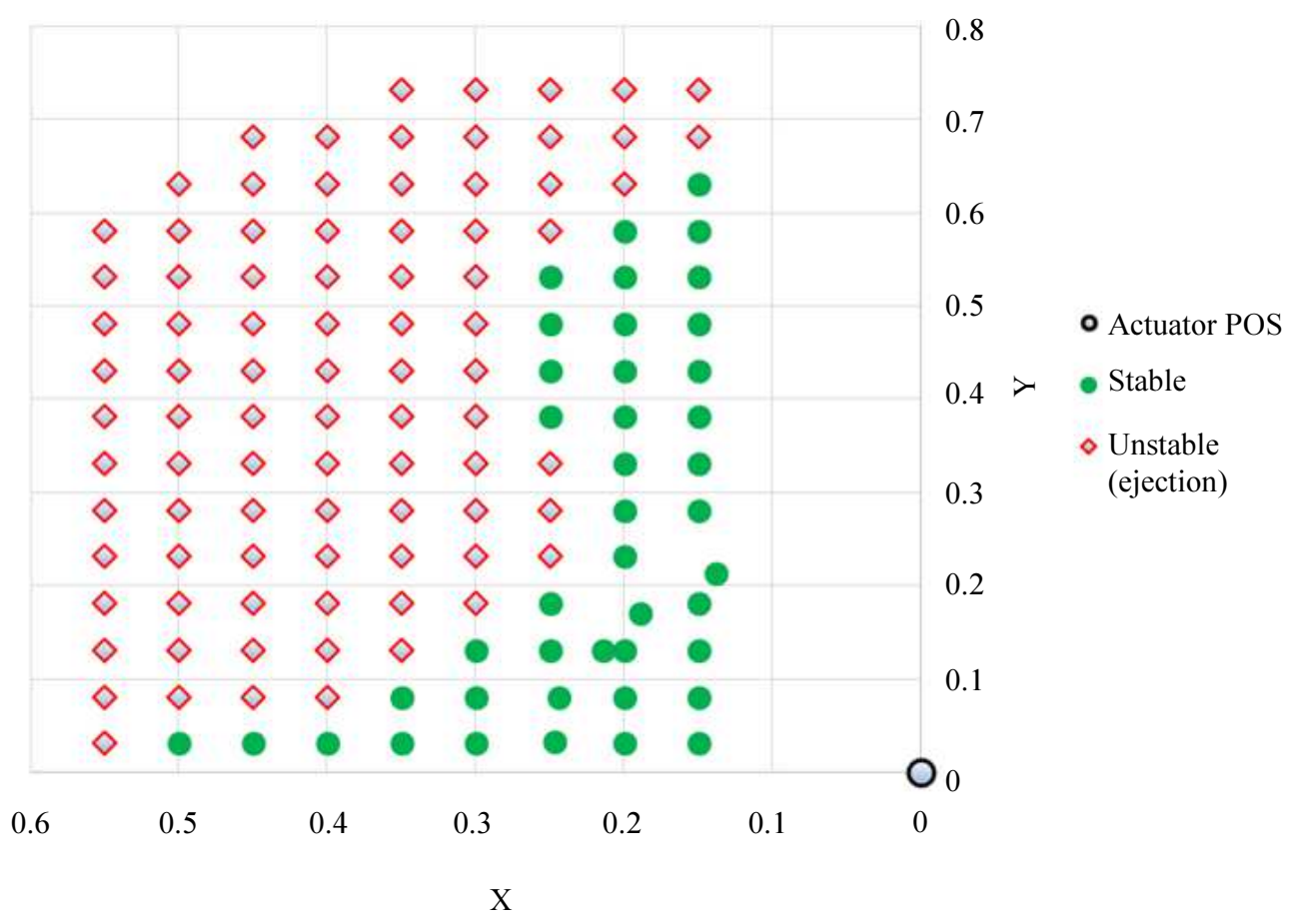

Fig. 16: Stability map for cylindrical object $d=240 \mathrm{~mm}$

\section{Conclusion}

After obtaining the required results both theoretically and experimentally the following concluding remarks can be withdrawn:
1. Grasping forces calculated theoretically, observed from the simulation procedure or measured experimentally, showed almost the same trend of variation as related to the cylindrical object location on the working space of the underactuated robotic manipulator 
2. Grasping forces attained higher values when the cylindrical grasped object is located near the fixed center of rotation of the underactuated robotic manipulator

3. In general, each grasping force decreases as the grasped cylindrical object diameter increases for any specific location of the grasped object

4. The state of stable grasping happened to be true when the grasped object is near the fixed axis of rotation of the robotic manipulator, while the state of ejection occurred when the object is far from the fixed axis of rotation in which contact between the object and the manipulator happened to be at the distal link

5. The probability of achieving a state of stable grasping is higher for smaller cylindrical grasped objects

\section{Acknowledgment}

The authors would like to acknowledge the workshop of the Manufacturing Automation Department at Alkhwarizmi College of Engineering for their help and support in the fabrication of the test rig.

\section{Author's Contribution}

Somer Nacy: Designed the research plan and organized the study. Coordinated the data analysis. Supervised the experimental work and the simulation analysis.

Ahmed Nayif: Fabrication of the experimental rig and obtained the experimental results. Building the simulation model. Contributed in analyzing the experimental and theoretical results.

\section{Ethics}

This article is original. Authors declare that there are no ethical issues that may arise after publication.

\section{References}

Azlan, N.Z. and Y. Hiroshi, 2010. Underactuated anthropomorphic finger mechanism for grasping and pinching with optimized parameter. J. Comput. Sci., 6: 928-933. DOI: $10.3844 /$ jcssp.2010.928.933

Birglen, L. and C.M. Gosselin, 2004. Optimal design of 2phalanx underactuated fingers. Proceedings of the International Conference on Intelligent Manipulation and Grasping, (IMG' 04), Genoa, Italy, pp: 110-114.

Birglen, L. and C.M. Gosselin. 2005. Geometric design of three-phalanx underactuated fingers. J. Mechanical Design, 128: 356-364. DOI: 10.1115/1.2159029

Birglen, L., T. Laliberté and C.M. Gosselin, 2008. Underactuated Robotic Hands. 1st Edn., Springer Science and Business Media, Berlin, ISBN-10: 3540774580, pp: 244.
Cabas, R., L.M. Cabas and C. Balaguer, 2006. Optimized design of the underactuated robotic hand. Proceedings of the International Conference on Robotics and Automation, May 15-19, IEEE Xplore Press, Orlando, FL, USA, pp: 982-987. DOI: $10.1109 /$ ROBOT.2006.1641837

Carrozza, M.C., C. Suppo, F. Sebastiani, B. Massa and F. Vecchi et al., 2004. The SPRING hand: Development of a self-adaptive prosthesis for restoring natural grasping. Autonomous Robots, 16: 125-141. DOI: 10.1023/B:AURO.0000016863.48502.98

Dandash, G., R. Rizk, S. Krut and E. Dombre, 2011. A pseudo-isotropic three phalanxes under-actuated finger. Proceedings of the13th World Congress in Mechanism and Machine Science, Jun. 19-25, Guanajuato, México.

Dechev, N., W.L. Cleghorn and S. Naumann, 2001. Multiple finger, passive adaptive grasp prosthetic hand. Mechanism Machine Theory, 36: 1157-1173. DOI: 10.1016/S0094-114X(01)00035-0

Ha, X.V., C. Ha and D.K. Nguyen, 2016. A general contact force analysis of an under-actuated finger in robot hand grasping. Int. J. Adv. Robot. Syst., 13: 1-17. DOI: $10.5772 / 62131$

Jung, T.J. and J.H. Oh, 2013. Design of a robot gripper for a rapid service robot. Proceedings of the 6th Symposium on Mechatronic Systems, Apr. 10-12, IFAC, Hangzhou, China, pp: 319-323.

Kim, E.H., M.T. Lim and Y.K. Lee, 2010. Analysis grasp stability for multi-fingered robot hand. Proceedings of the International Conference on Control Automation and Systems, Oct. 27-30, IEEE Xplore Press, Gyeonggi-do, South Korea.

DOI: 10.1109/ICCAS.2010.5670144

Kragten, G.A. and J.L. Herder, 2007. Equilibrium, stability and robustness in underactuated grasping. Proceedings of the International Design Engineering Technical Conferences on Computers and Information in Engineering Conference, Sept. 4-7, Las Vegas, Nevada, USA, pp: 645-652.

DOI: $10.1115 /$ DETC2007-34963

Kragten, G.A., 2011. Underactuated hands, fundamentals, performance analysis and design. Ph.D. Thesis, TU Delft.

Kragten, G.A., M. Baril, C. Gosselin and J.L. Herder, 2011. Stable precision grasps by underactuated grippers. IEEE Trans. Robot., 27: 1056-1066. DOI: $10.1109 /$ TRO.2011.2163432

Krut, S., 2005. A force-isotropic underactuated finger. Proceedings of International Conference on Robotics and Automation, Apr. 18-22, IEEE Xplore Press, Barcelona, Spain, pp: 2314-2319. DOI: 10.1109/ROBOT.2005.1570458 
Laliberté, T. and C. Gosselin, 2003. Actuation system for highly underactuated gripping mechanism. US Patent, US 6,505,870 B1.

Laliberte, T., L. Birglen and C.M. Gosselin, 2002. Underactuation in robotic grasping hands. Machine Intelligence Robot. Control, 4: 1-11.

Luo, M., T. Mei, X. Wang and Y. Yu, 2004. Grasp characteristics of an underactuated robot hand. Proceedings of the International Conference on Robotics and Automation, Apr. 26-May 1, IEEE Xplore Press, New Orleans, LA. DOI: 10.1109/ROBOT.2004.1307394

Meijneke, C., G.A. Kragten and M. Wisse, 2011. Design and performance assessment of an underactuated hand for industrial applications. Mechanical Sci., 2: 9-15. DOI: $10.5194 / \mathrm{ms}-2-9-2011$

Nacy, S.M. and A.A. Nayif, 2016. Simulation analysis of grasping forces for a 3-DOF robotic manipulator. Innovat. Syst. Design Eng., 7: 35-39.

Nacy, S.M., S.S. Hassan and S.H. Bakhy, 2009. Geometric optimization of three-phalanx prosthesis underactuated fingers using particles swarm algorithm. Am. J. Eng. Applied Sci., 2: 381-387. DOI: 10.3844/ajeassp.2009.381.387

Rea, P., 2011. On the Design of Underactuated Finger Mechanisms for Robotic Hands. In: Advances in Mechatronics, H. Martinez-Alfaro (Ed.), IntechOpen, ISBN-13: 978-953-307-373-6, pp: 132-154.
Rizk, R., S. Krut and E. Dombre, 2007. Grasp-stability analysis of a two-phalanx isotropic underactuated finger. Proceedings of the International Conference on Intelligent Robots and Systems., Oct. 29-Nov. 2, IEEE Xplore Press, San Diego, CA, USA.

DOI: $10.1109 /$ IROS.2007.4399169

Yang, J., E.P. Pitarch, K.A. 1-Malek, A. Patrick and L. Lindkvist, 2004. A multi-fingered hand prosthesis. Mechanism Machine Theory, 39: 555-581. DOI: 10.1016/j.mechmachtheory.2004.01.002

Yao, S. and M. Ceccarelli, 2011. Analysis and optimal design of an underactuated finger mechanism for LARM hand. Frontiers Mechanical Eng., 6: 332-343.

Zhang, W., D. Che, Q. Chen and D. Du, 2009. Grasping process analysis on gesture-changeable under-actuated mechanical finger. Proceedings of the International Conference Modeling, Simulation and Identification (MSI' 09), IASTED, Beijing, China.

Zhao, D. and W. Zhang, 2010. Changeable Grasping Force unit for Under-Actuated Gripper with SelfAdaptive Grasping. In: Intelligent Robotics and Applications, Liu, H., H. Ding, Z. Xiong and X. Zhu (Eds.), Springer Berlin Heidelberg, China, pp: 13-25. 